Çukurova Üniversitesi Mühendislik Mimarlık Fakültesi Dergisi, 35(3), ss. 813-820, Eylül 2020

Cukurova University Journal of the Faculty of Engineering and Architecture, 35(3), pp. 813-820, September 2020

\title{
Alternatif FML Kompozitler için Titanyum ve Elyaf/Epoksi Ara Yüzey Dayanımının İncelenmesi
}

\author{
Mete Han BOZTEPE ${ }^{* 1}$, Melih BAYRAMOĞLU ${ }^{1}$, Çağrı UZAY², Necdet GEREN ${ }^{1}$ \\ ${ }^{1}$ Çukurova Üniversitesi, Mühendislik Mimarlık Fakültesi, Makine Mühendisliği Bölümü, Adana \\ ${ }^{2}$ KahramanmaraşS Sütçü İmam Üniversitesi, Mühendislik Mimarlık Fakültesi, Makine \\ Mühendisliği Bölümü, Kahramanmaraş
}

Geliş tarihi: 22.09 .2020

Kabul tarihi: 23.10 .2020

Öz

Elyaf takviyeli polimer kompozit yapılar, hafifliğin yanı sıra yüksek mukavemete sahip olup nem, korozyon gibi çevresel etmenlere karşı direnç gösterirler ancak ani darbe yüklerine karşı zayıf ve kırılgandır. Bu yüzden araştırmacılar özellikle uzay-havacılık ve savunma sanayi alanları için elyaf ve metal malzemeleri bir arada lamine ederek FML (Fiber Metal Laminate) kompozitleri geliştirmişlerdir. FML kompozitler elyaf ve metallerin avantajlarını bir araya getirirken dezavantajlarını ise elimine etmektedir. Fakat elyaf ve metal katmanların ara yüzey dayanımının tespiti FML kompozitin etkinliği üzerinde önemli rol oynamaktadır. Bu çalışmada metal olarak TiGR2 serisi titanyum ve elyaf olarak $\pm 45^{\circ}$ oryantasyonlu karbon ve cam kullanılarak ASTM D 5868 standardına göre üretilen kompozitlerin ara yüzey dayanımları araştırılmıştır. Vakum torbalama yöntemi ile üretilen elyaf kompozitlerde kullanılan epoksi matris malzemesi metal yüzeylerin yapıştırılmasında da kullanılmıştır.

Anahtar Kelimeler: Elyaf metal katmanlı kompozit (FML), Titanyum, Ara yüzey dayanımı, Tek bindirmeli kayma testi

\section{Investigating the Interfacial Strength of Titanium and Fiber/Epoxy for The Alternative FML Composites}

\begin{abstract}
Fiber-reinforced polymer composites provide high strength to weight ratio, resist to environmental effects, but they have poor impact strength due to brittleness. Therefore, researchers have developed fiber metal laminates (FMLs) particularly for aerospace, aviation and defence industries. FML composites combine the advantages of both metal alloys and fibers but eliminate their drawbacks. However, the bonding strength of fiber-metal interface plays an important role for effectiveness of FML composites. In this study, the interfacial strength values of TiGr2 series titanium sheets and $\pm 45^{\circ}$ oriented fiber/epoxy composites (glass and carbon) were investigated by applying single lap shear tests based on ASTM D 5868. Epoxy based adhesive was used as a matrix during manufacturing for joining titanium sheets to composite laminates.
\end{abstract}

Keywords: Fiber metal laminated composite (FML), Titanium, Single lap shear test, Interfacial strength

*Sorumlu yazar (Corresponding author): Mete Han BOZTEPE, mboztepe@cu.edu.tr 


\section{GIiRiş}

Elyaf takviyeli polimer kompozit yapılara olan talep onların üstün mekanik özelliklerinden dolayı gün geçtikçe artmaktadır. En az iki malzemenin bir araya gelerek avantajlarını bir yapıda birleştirdiği, dezavantajlarını elimine ettiği kompozit yapılar, genellikle uzay-havacılık, otomotiv, denizcilik, savunma, spor ekipmanları gibi endüstrilerde kullanımı giderek yaygınlaşmaktadır [1].

FRP (fiber-reinforced polymer) kompozitlerinin birçok avantajının yanısıra metalik malzemelere kıyasla daha düşük yük taşıma (bazı elyaf dizilimlerinde) ve düşük darbe dayanımı gibi özelliklere sahiptirler. Bu dezavantajları nedeniyle, Elyaf Metal Katmanlı (FML'ler) olarak adlandırılan ve cam, karbon, kevlar takviyeli geleneksel kompozitlere göre daha yenilikçi sayılan kompozit malzeme türü geliştirilmiştir. Elyaf metal katmanlı FML'ler yüksek performanslı hibrit yapılar olup uçakların gövde, kanat, kuyruk ve motor taşıma yapılarında yoğun olarak kullanılan malzemelerdir. Tipik bir FML, Şekil 1'de gösterildiği gibi ince metal alaşımı ile sentetik lif takviyeli polimer matrislerden oluşmaktadır [2-4].

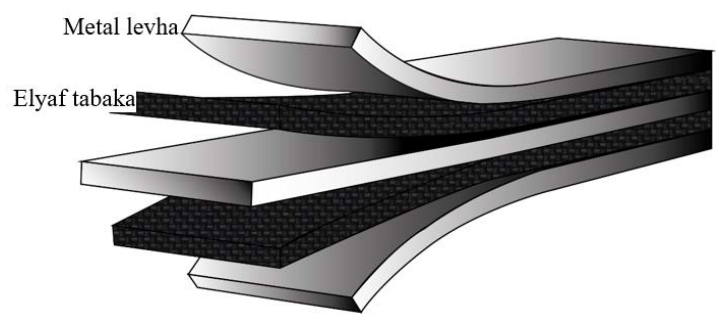

Şekil 1. Elyaf Metal Katmanlı

(FML) kompozitlerin gösterimi

FML kompozitler, literatürde ve endüstriyel uygulamalarda Glare (cam elyaf-alüminyum), Arall (aramid-alüminyum) ve Carall (karbon elyaf -alüminyum) ticari isimleri ile farklı standart kalitelerde bulunmakta olup matris malzeme olarak istenilen özellikleri sağlaması sebebiyle genellikle epoksi reçine ve ona uygun sertleştirici malzemeler tercih edilmektedir. FML kompozitler ve türleri Şekil 2'deki gibi sınıflandırılmıştır [5]. Yapılan araştırmalar Arall ve Carall'ın hala geliştirilmeye muhtaç olduğunu gösterirken, cam elyafı içeren Glare'in darbe yükü altındaki davranışının diğerlerine göre daha iyi olduğunu göstermiştir [6]. Bu da kompozit yapıdaki ara yüzey dayanımlarının FML tipine ve kullanılan malzemelere bağlı olduğunu göstermektedir.

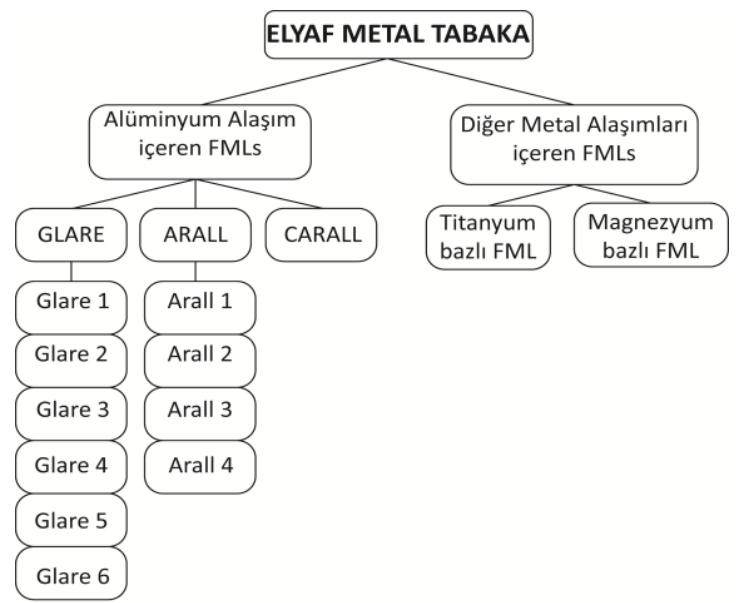

Şekil 2. FML kompozitlerin sınıflandırılması

FML kompozitlerde metallerin varlığı yapıya yüksek tokluk kazandırdığı için darbe dayanımı iyileştirmekte elyaflar ise dinamik yükler altında çatlak ilerlemesine engel olmaktadır. Bu durum yapılarda yorulma performansinı ve hasar toleransını kayda de ğer artırdığından dolayı FML kompozit malzemeleri ön plana çıkarmaktadır [7-10].

Özellikle uzay-havacılık ve savunma sanayi gibi alanlarda kompozit yapının yüksek sıcaklıklarda da mekanik özelliklerini koruyabilmesi için daha kararlı yapıda olan titanyum levhaların bilinen FML kompozitlere alternatif olabileceği yönünde çalışmalar bulunmaktadır. Çünkü alüminyum bazlı FML kompozitlerin yüksek sicaklıklarda yetersiz sürünme (creep) dirençleri sebebiyle istenilen mekanik özellikler elde edilememektedir. Ayrıca çevresel etmenlere karşı da titanyum levhaların kararlı yapıları onların diğer avantajlarındandır [11]. Jin ve arkadaşları [12] FML kompozitin yüksek sıcaklıklarda da yüksek darbe direnci ve yorulma dayanımı sağlaması için titanyum levha ve cam elyaftan FML üretimi yapmışlar ve farklı sıcaklıklarda katmanlar arası ayrılma hasarlarını 
inceleyerek yorulma davranıșını sıcaklığa bağlı denklemler ile tarif etmişlerdir. Araştırmacılar titanyum bazlı FML kompozitleri genellikle sıcaklığa bağlı yorulma yükleri altındaki davranışlarını incelemişlerdir ancak çekme, eğilme, ara yüzey bağ mukavemeti gibi diğer mekanik özellikler hakkında yapılan çalışmalar sinırlıdır. Bourlegat ve arkadaşları [13] titanyum bazlı FML kompozitin GLARE ve CARALL tipi FML malzemelere göre oldukça yüksek çekme dayanımına sahip olduğunu göstermiştir.

FML tipi kompozitlerde katmanlar arası dayanımın araştırılması için genellikle tek bindirmeli kayma testine başvurulur. Bora ve arkadaşları [14] 2024 serisi alüminyum alaşımlı levha ile tek yönlü karbon/epoksi kompozit tabakaları Loctite marka epoksi bazlı yapıştırıcı ile yapıştırmış ve kayma dayanımını test etmiştir. Yaklaşık 6,5 $\mathrm{MPa}$ elde edilen ara yüzey dayanımı daha sonra silan ve elyaf lazer işlemleri ile yüzey iyileştirmeleri yaparak bu dayanımı artırmışlardır. Logesh ve arkadaşları [15] cam elyaf ve alüminyum 5052 serisi alaşım levha y1 epoksi matris ile FML üretimi yapmışlardır. Ayrıca çok duvarlı karbon nano tüpler (KNT) kullanarak yapıdaki mekanik değişiklikleri de incelemişlerdir. Tek bindirmeli kayma test sonuçlarına göre KNT içermeyen numuneler en fazla $908 \mathrm{~N}$ taşırken, ağırlıkça \%3 KNT içeren yapı $1170 \mathrm{~N}$ ile en fazla yükü taşımıştır, \%5 KNT içeren yapı ise $210 \mathrm{~N}$ yük taşıdığı görülmüştür. Zhang ve arkadaşları [16] karbon elyaf ve polyamid reçine ile tabakalandırdığı komozit yapıyı TA2 serisi titanyum levha ile yapıştırmış ve kayma testinde 5,6 MPa dayanım elde etmiştir. Dayanımı artırmak için yapıya belirli oranlarda çok duvarlı KNT ilave etmiş ve testleri tekrarlamıştır. En fazla dayanım $\% 5 \mathrm{KNT}$ içeren yapının testinde ortalama 9,87 $\mathrm{MPa}$ olarak bulunmuştur.

Bu çalışmada, bilinen FML kompozitlere alternatif olabilmesi amaciyla $\pm 45^{\circ}$ elyaf oryantasyonuna sahip cam ve karbon elyaflar ile TiGr2 serisi titanyum malzemelerin ara yüzey bağ mukavemeti araştırılmıştır. Çalışma iki aşamadan oluşmaktadır. Öncelikle vakum torbalama yöntemi ile cam/epoksi ve karbon/epoksi kompozit tabakalar üretilmiş ardından ASTM D 5868 [17] standardına göre hazırlanan kompozit ve metal levhalar yine aynı üretim yöntemi ile üretilen tek bindirmeli kayma numuneleri elde edilmiştir. Standarda uygun olarak yapılan testler neticesinde farklı metal içeren alternatif FML uygulamalarına örnek olabilecek sonuçlar sunulmuştur.

\section{MATERYAL VE METOT}

\subsection{Materyal}

Çalışmada metal olarak Titanyum-TiGR2 serisi ve elyaf olarak da $\pm 45^{\circ}$ dizilimli karbon ve cam elyaflar kullanılmıştır. Çizelge 1 'de titanyumun kimyasal kompozisyonu, Çizelge 2'de ise elyafların fiziksel özellikleri verilmiştir.

Çizelge 1. TiGR2 serisi titanyumun kimyasal kompozisyonu

\begin{tabular}{|c|c|c|c|}
\hline \% $\mathbf{~ T i}$ & \% $\mathbf{C}$ & $\mathbf{\%} \mathbf{F e}$ & $\mathbf{\%} \mathbf{~}$ \\
\hline 99 & 0,08 & 0,3 & 0,03 \\
\hline
\end{tabular}

Çizelge 2. Karbon ve cam elyafların fiziksel özellikleri

\begin{tabular}{|c|c|c|}
\cline { 2 - 3 } \multicolumn{1}{c|}{} & $\begin{array}{c}\text { Yoğunluk } \\
\left(\mathbf{g} / \mathbf{m}^{\mathbf{2}}\right)\end{array}$ & Kalınlık $(\mathbf{m m})$ \\
\hline Karbon $\mathbf{\pm 4 5}^{\circ}$ & 300 & 0,40 \\
\hline Cam $\mathbf{\pm 4 5 ^ { \circ }}$ & 468 & 0,42 \\
\hline
\end{tabular}

\subsection{Metot}

Hem elyaf takviyeli kompozitlerin hem de tek bindirmeli kayma test numunelerinin üretimi farklı aşamalarda vakum torbalama yöntemi uygulanarak gerçekleştirilmiştir. Aslında FML kompozitler her elyaf katmanları arasına metal plakaların yerleştirilmesi ile üretilirken bu çalışmada alternatif FML üretimine öncü olabilecek, bilinenden farklı metal yüzeyin elyaf kompozitler ile arasındaki tutunma dayanımının incelenecek olmasından dolayı, iki aşamalı bir üretim yöntemi tercih edildi. Bunlardan ilki sadece elyaf katmanlarının (cam FRP ve karbon FRP) üretiminin yapılması ikincisi ise üretilen FRP plakalar ile titanyum plakaların kompozit üretiminde kullanılan bağlayıcı matris ile birleştirilmesidir. 


\subsubsection{Elyaf Tabakalı Kompozit (FRP) Üretimi}

Vakum torbalama yöntemine göre gerçekleştirilen FRP üretimlerinde reçine olarak L160 epoksi ve H160 sertleștiricisi malzemelerin ağırlıkça 100:25 oranında karıştırılarak elde edilen matris malzemesi kullanılmıștır. Toplam kullanılacak matris miktarı ise üretilecek FRP plakaların elyaf ağırlı̆̆ına eşit olacak şekilde hazırlandı. Cam ve karbon elyaf kumaşlar el yatırması ile açık düz kalıp üzerine istiflenmiştir. Bu işlem öncesinde FRP komozitlerin kalıtan kolaylıkla ayrılabilmesi için kalıp yüzeyi Polivaks malzeme ile kimyasal işleme tabi tutulmuştur. İstiflenen FRP plakaların üzerine sırası ile delikli ayırıcı film, vakum battaniyesi ve vakum torbası serilmiştir. Delikli ayırıc1 film, fazla reçinenin vakum battaniyesine geçmesine ve orada tutunmasını sağlamaktadır. FRP tabakalar sizdirmaz bant vasitasıyla vakum torbası altında kürlenmeye bırakılmıştır. FRP kompozitlerin üretimi Şekil 3'te şematik olarak gösterilmektedir. Kürlenme işlemi oda sıcaklığında ve 24 saat süreyle gerçekleştirilmiştir.

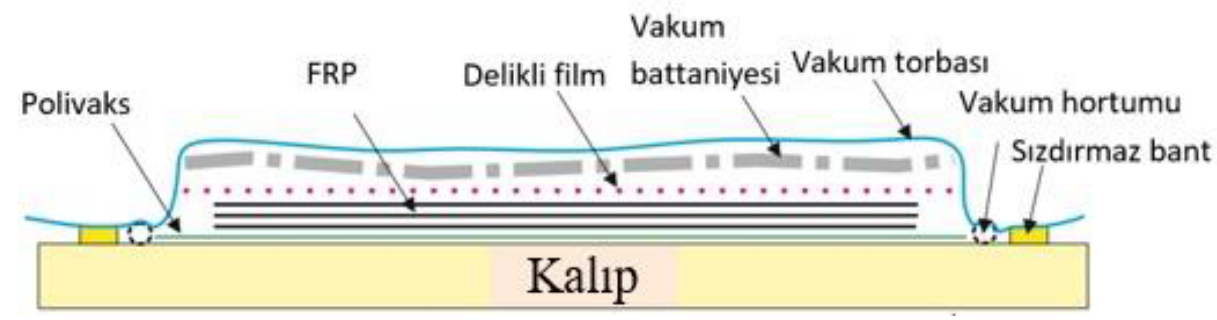

Şekil 3. Uygulanan vakum torbalama yönteminin şematik gösterimi

\subsubsection{FRP Plakaların ve Metal Levhaların Hazırlanması}

Kürlenme işleminden sonra vakum atmosferinden çıkarılan plakaların ve titanyum levhanın boyut hassasiyetlerinin korunması için su jeti ile standart test numunesi (ASTM D 5868-01 "Yüzey Kayma Testi') boyutlarında kesilmiştir. Şekil 4'te şematik olarak standart test numunesi boyutları, Şekil 5'te de su jeti kesimi gösterilmiştir.

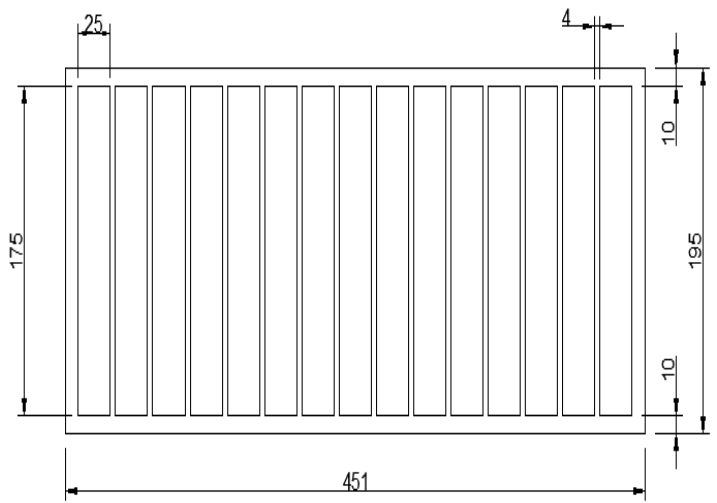

Şekil 4. FRP plakalar ve titanyum levha için hazırlanan kesim şablonu

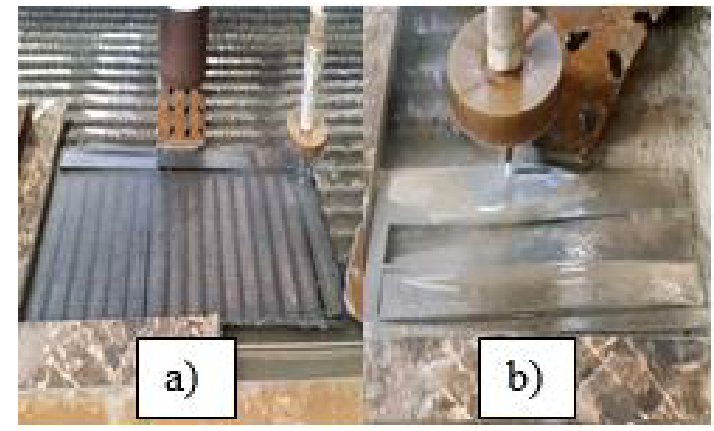

Şekil 5. Su jetinde kesimi yapılan FRP plakalar ve metal levha a) Karbon $\pm 45^{\circ}$ plaka, b) TiGR2 titanyum levha

\subsubsection{Tek Bindirmeli Kayma Test Numunelerinin Hazırlanması}

Üretimin son aşaması olarak tek bindirmeli kayma test numunelerinin üretimi gerçekleştirildi. Üretim esnasinda FRP numuneler ile titanyum numunelerin hassas bir șekilde birleștirilmesini kolaylaştırmak ve ASTM standardında belirtilen birleşme mesafesini $(25 \mathrm{~mm})$ ayarlamak amacıyla, Şekil 6'da gösterilen kalıp tasarlanmış ve MDF malzemeden üretilmiştir. 


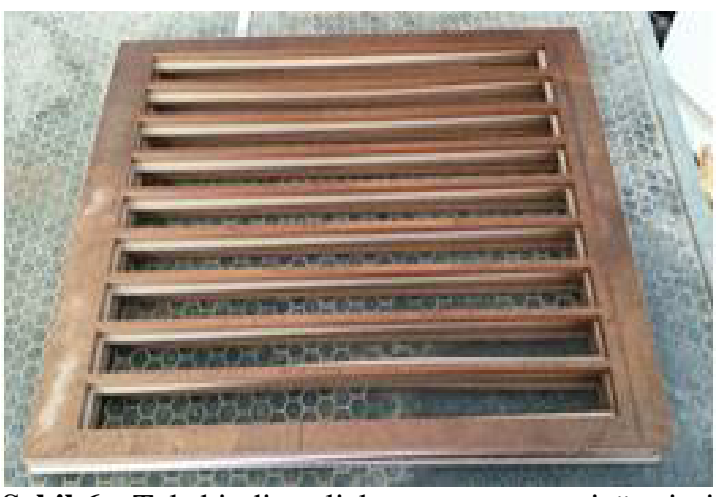

Şekil 6. Tek bindirmeli kayma numunesi üretimi için tasarlanan ve MDF den üretilen kalıp

Üretimde FRP ve metal plakalara ait numuneler MDF kalıp içerisinde yine aynı epoksi matris kullanılarak vakum altında birleştirildi. Kürlenme işlemi 24 saatte ve oda sicaklığında bekletilerek tamamlandı. Şekil 7'de kalıptan çıkarılan cam/epoksi-titanyum ve karbon/epoksi-titanyum tek bindirmeli kayma test numuneleri gösterilmektedir.

\section{a}

\section{b}

Şekil 7. Tek bindirmeli kayma testi numunesi a) cam/epoksi-titanyum, b) karbon/ epoksi-titanyum

\subsubsection{Numuneler için Ara Yüzey Bă̆ Mukavemeti Testi}

Titanyum levha ve farklı türden FRP kompozit katmanların ara yüzey bağ mukavemetinin tespiti için ASTM D 5868-01 "Yüzey Kayma Testi" uygulanmıştır. Bu teste ait numunelerin şematik gösterimi Şekil 8'de verilmiştir.

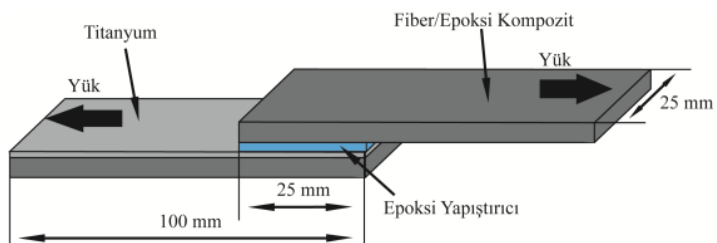

Şekil 8. Yüzey kayma testine ait numunelerin şematik olarak gösterimi
Test $13 \mathrm{~mm} / \mathrm{dk}$ hızında çekme yönünde kuvvet uygulanarak gerçekleştirilmiştir. Testler, Şekil 9'da görülen Shimadzu marka 100 kN kapasiteli çekme test cihazı kullanılarak gerçekleştirildi.

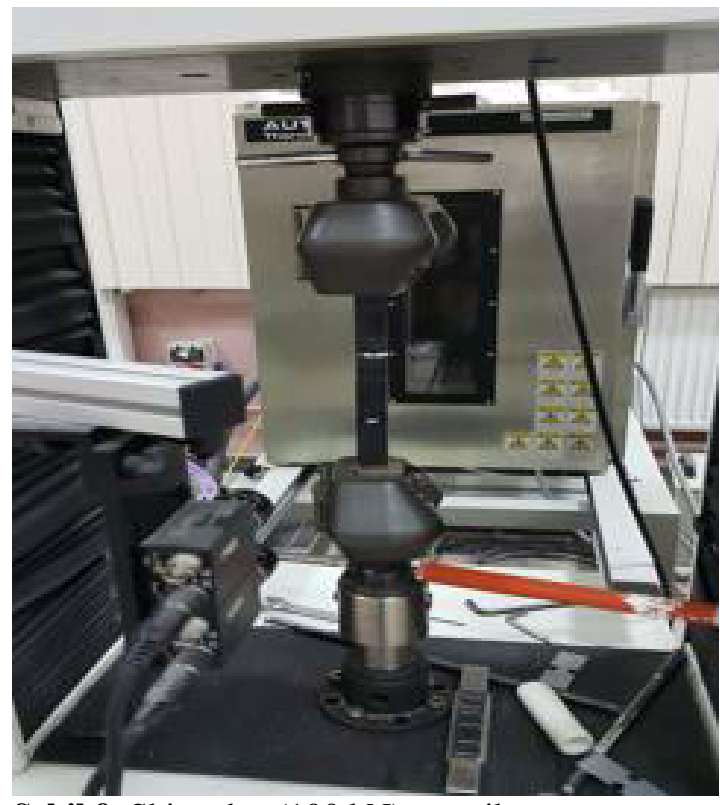

Şekil 9. Shimadzu $(100 \mathrm{kN})$ test cihazı

\section{BULGULAR}

Farklı türden yüzeylerin oluşturdu bağ mukavemetini araştırmak için TiGR2 serisi titanyum levha ve iki farklı FRP tipi $\left( \pm 45^{\circ}\right.$ elyaf dizilimli) ile tek bindirmeli kayma numunesi üretildi.

Her bir örneklemden üçer adet test numunesi elde edildi. Testler oda sıcaklığında gerçekleştirilmiştir. Testlerden elde edilen kuvvet-deplasman eğrileri Şekil 10'da verilmiştir. Yüzey ayrılma mukavemeti (LLS: Lap Shear Strength) ASTM 5868 standardına göre maksimum kopma yükünün (Pmax), tutunma yüzey alanına $\left(A=625 \mathrm{~mm}^{2}\right)$ oranı ile bulunmaktadır (Eşitlik 1). Farklı elyaf türleri ve titanyum levha için elde edilen yüzey tutunma dayanımına ait bulgular Çizelge 3 'te verilmiştir. Cam/epoksi-titanyum numuneler yaklaşık $677 \mathrm{~N}$ yük taşırken karbon/epoksititanyum numuneler yaklaşık $1539 \mathrm{~N}$ yük 
taşımıştır. $\mathrm{Bu}$ da polimer epoksi matrisin karbon/epoksi ve titanyum levhaların yapıştırılması durumunda daha iyi sonuçlar verdiğini göstermektedir. Ancak elyaf takviyeli kompozit tabakalar ile herhangi bir yüzey işlemi görmemiş titanyum levha ara yüzeyindeki bağ mukavemetinin düşük olması, kompozit üretiminde kullanılan epoksi reçinenin titanyum levhayı yapıştırmada çok da etkili olamadığını göstermiştir. Zira Tan ve arkadaşları [18] karbon elyaf ve PEEK reçine ile tabakalandırdığı kompozit yapıyı titanyum alaşıma yapıștırmış ve taşıdığı yükü 1024 N olarak bulmuştur. Buna karşın, Bora ve arkadaşları [14] silan ve elyaf lazer işlemleri gibi yüzey iyileştirme işlemleri ile; Logesh ve arkadaşları [15], Zhang ve arkadaşları [16] ise matris yapısına çok duvarlı KNT ilave ederek ara yüzey dayanımının arttığını göstermişlerdir.

$\mathrm{LSS}=\frac{\mathrm{P}_{\max }}{\mathrm{A}}$

Çizelge 3. Farklı elyaf türleri ve titanyum metali için elde edilen yüzey tutunma test sonuçları

\begin{tabular}{|c|c|c|c|c|c|}
\hline $\begin{array}{l}\text { FRP plaka- } \\
\text { Titanyum levha }\end{array}$ & $\begin{array}{l}\mathbf{P}_{\max } \\
(\mathbf{N})\end{array}$ & $\begin{array}{l}\text { Ortalama } \\
\mathbf{P}_{\max }(\mathbf{N})\end{array}$ & $\begin{array}{l}\text { Yüzey Tutunma } \\
\text { Mukavemeti } \\
\text { (LSS) (MPa) }\end{array}$ & $\begin{array}{c}\text { Ortalama } \\
\text { LSS (MPa) }\end{array}$ & $\begin{array}{c}\text { Standart } \\
\text { Sapma }\end{array}$ \\
\hline \multirow{3}{*}{ Cam/epoksi - Ti } & 693 & \multirow{3}{*}{677} & 1,11 & \multirow{3}{*}{1,08} & \multirow{3}{*}{0,11} \\
\hline & 582 & & 0,93 & & \\
\hline & 756 & & 1,21 & & \\
\hline \multirow{3}{*}{ Karbon/epoksi - Ti } & 1727 & \multirow{3}{*}{1539} & 2,76 & \multirow{3}{*}{2,46} & \multirow{3}{*}{0,26} \\
\hline & 1563 & & 2,50 & & \\
\hline & 1328 & & 2,12 & & \\
\hline
\end{tabular}

Daha önce yapılan bir araştırmada [19] titanyum bazlı levhalar ile $0^{\circ} / 90^{\circ}$ elyaf dizilimli cam ve karbon kumaşlardan üretilen kompozit tabakalar ve düz dokuma aramid kumaştan üretilen kompozit tabakaların tek bindirmeli kayma testleri yapılmıştır. Test sonuçlarından elde edilen veriler bu çalışmanın sonuçları ile birlikte karşılaştırmalı olarak Şekil 8'de sunulmaktadır. Hem elyaf türünün hem de elyaf oryantasyonun sonuçlar üzerindeki etkisi ortaya çıkarılmıştır. Bu çalışmada kullanılan $\pm 45^{\circ}$ dizilimli kumaşların titanyum levha ile daha iyi bir tutunma yüzeyi sağladığı ve bu sebeple kayma gerilmelerine karşı daha dirençli olduğu görülmektedir.

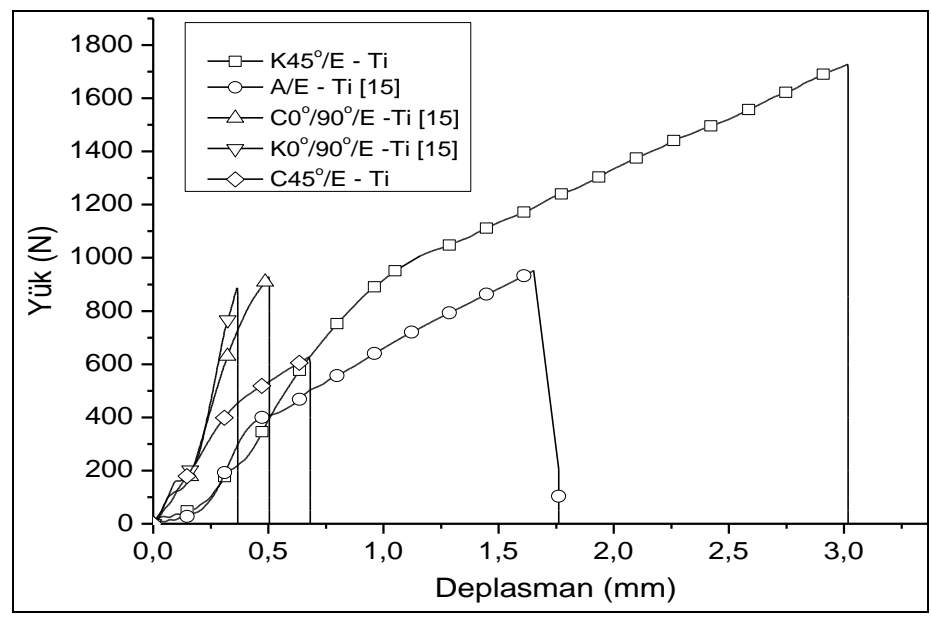

Şekil 10. Tek bindirmeli kayma testi yük-deplasman eğrileri ve literatür ile kıyaslama (K: karbon, A: Aramid, C: Cam, E: Epoksi, Ti: Titanyum) 
Testler sonrasında yüzeyleri birbirinden ayrilan numuneler makro düzeyde fotoğraf makinesi ile gözlemlenmiş ve titanyum ve Cam/epoksi plakanın tutunma yüzeylerindeki epoksinin dağılımı Şekil 11 ve 12'da gösterilmiştir. Cam/epoksi tabakası üzerinde fazla epoksi biriktiği ve buna karşın karbon/epoksi tabakasında daha ince bir epoksi tabakasının olduğu ve bunun da LSS verileri ile uyumlu olduğu tespit edilmiştir. Çünkü epoksi matrisin dayanımının elyaf ve titanyum malzemelere göre nispeten daha düşük olması sebebiyle cam/epoksi tabakada biriken fazla miktardaki polimer matris malzemesi kompozit yapının dayanımını da olumsuz etkilemektedir.
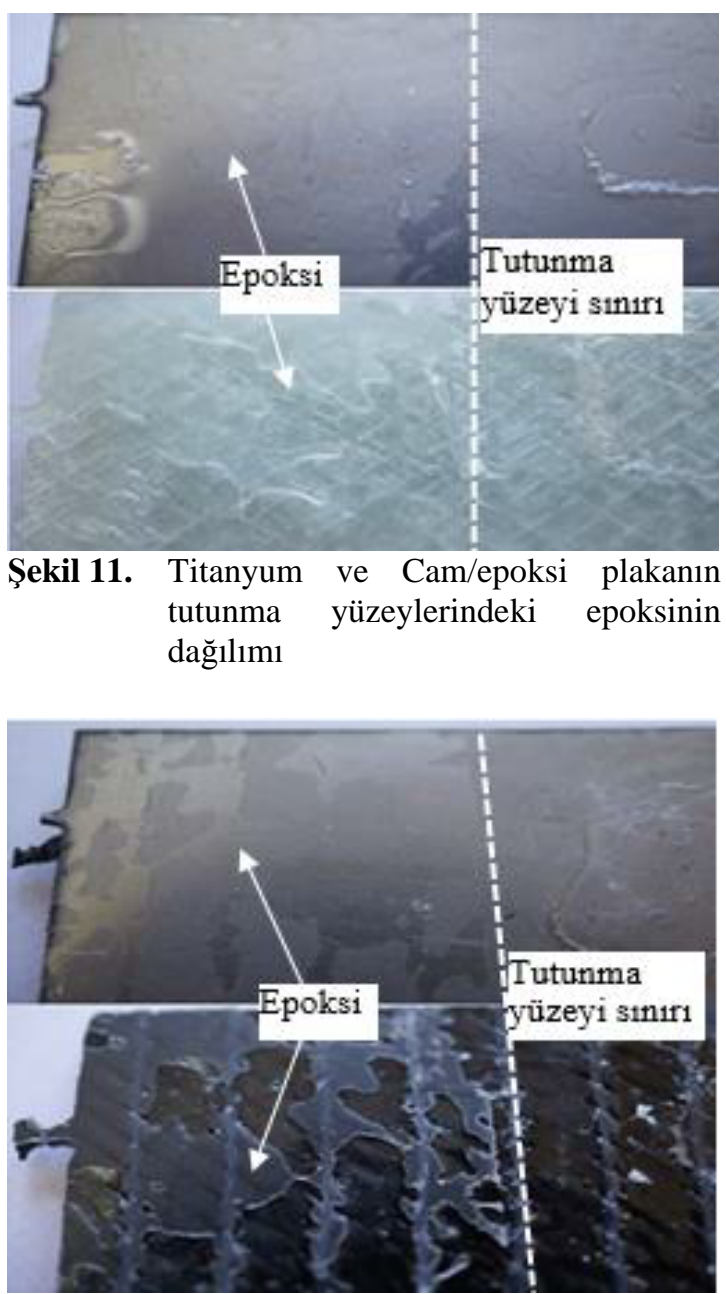

Şekil 12. Titanyum ve karbon/epoksi tutunma yüzeylerindeki epoksinin dağglımı

\section{TARTIŞMA VE SONUÇ}

FML kompozitlerde hasar oluşumu, malzemenin hangi yükler altında çalıştığına, ara yüzey malzemelerin uyumluluğuna ve çevresel etmenlere göre değişiklik gösterebilir. FML üzerine yapılan literatür çalışmalarına bakıldığında en fazla problemin metal ile elyaf tabaka arasındaki tutunma yüzeylerinde olduğu görülmektedir. Yüzey tabakaları arasındaki tutunma bağının fiziksel durumu, FML kompozitlerin mekanik özelliklerini önemli derecede etkilemektedir. Farklı türden metal levha kullanımı gibi çalışmaların yanı sıra katmanların tutunma yüzeylerini iyileştirme konusunda da çalışmalar yapılmaktadır. Ayrıca literatürdeki FML çalışmaları ağırlıklı olarak alüminyum üzerinde yoğunlaştığı ancak titanyum gibi alternatif metallerin FML'de kullanımıyla ilgili büyük bir boşluk olduğu görülmektedir. $\mathrm{Bu}$ çalışmanın sonuçları bilinen FML kompozitlere alternatif oluşturabilecek titanyum levhaların kullanımı noktasında araştırmacılara yol gösterici olacaktır. İlaveten, bazı yüzey iyileştirme metotlarının [20] titanyum alaşımlı levhalar ile kompozit tabakalar arasındaki bağ mukavemetine etkisinin araştırtılması ve farklı türden yapıştırıcılar ile arayüzey bağ mukavemeti testlerinin yapılması bu çalışmanın devamı niteliğinde önerilebilir.

\section{TEŞEKKÜR}

$\mathrm{Bu}$ çalışma, FBA-2017-8929 nolu proje kapsamında Çukurova Üniversitesi Bireysel Araştırma Projesi (BAP) Koordinasyon Birimi tarafından desteklenmiştir.

\section{KAYNAKLAR}

1. Shetty, N., Shahabaz, S.M., Sharma, S.S., Shetty, S.D., 2017. A Review on Finite Element Method for Machining of Composite Materials, Composite Structures, 176, 790-802.

2. Chandrasekar, M., Ishak, M.R., Jawaid, M., Leman, Z., Sapuan, S.M., 2017. An Experimental Review on the Mechanical Properties and Hygrothermal Behaviour of Fibre Metal Laminates, Journal of Reinforced Plastics and Composites, 36(1), 72-82. 
3. Corte's, P., Cantwell, W.J., 2006. The Prediction of Tensile Failure in Titanium-based Thermoplastic Fibre-metal Laminates, Composites Science and Technology, 66, 2306-2316.

4. Remmers, J.C., 2006. Discontinuities in Materials and Structures: a Unifying Computational Approach, PhD Thesis, Delft University of Technology.

5. Sinmazçelik, T., Avcu, E., Bora, M.Ö., Çoban, O., 2011. A Review: Fibre Metal Laminates, Background, Bonding Types and Applied Test Methods, Materials and Design, 32, 36713685.

6. Vlot, A., 1996. Impact Loading on Fibre Metal Laminates, Int J Impact Eng, 18(3), 291-307.

7. Wang, W., Rans, C., Benedictus, R., 2017. Analytical Prediction Model for Nonsymmetric Fatigue Crack Growth in Fibre Metal Laminates, International Journal of Fatigue, 103, 546-556.

8. Vogelesang, L.B., Vlot, A., 2000. Development of Fibre Metal Laminates for Advanced Aerospace Structures, Journal of Materials Processing Technology, 103, 1-5.

9. Sadighi, M., Alderliesten, R.C., Benedictus, R., 2014. Impact Resistance of Fiber-Metal Laminates: A Review, International Journal of Impact Engineering, 49, 77-90.

10. Laliberte, J.F., Poon, C., Straznicky, P.V., Fahr, A., 2000. Applications of Fiber-Metal Laminates, Polymer Composites, 21, 558-567.

11. Kazemi, M.E., Shanmugam, L., Yang, L., Yang, J., 2020. A Review on the Hybrid Titanium Composite Laminates (HTCLs) with Focuses on Surface Treatments, Fabrications, and Mechanical Properties, Composites Part A: Applied Science and Manufacturing, 128.

12. Jin, K., Chen, K., Luo, X., Tao, J., 2020. Fatigue Crack Growth and Delamination Mechanisms of Ti/CFRP Fibre Metal Laminates at High Temperatures. Fatigue Fract Eng Mater Struct. 43: 1115-1125.

13. Le Bourlegat, L., Damato, C., da Silva, D., Botelho, E., Pardini, L., 2010. Processing and Mechanical Characterization of Titaniumgraphite Hybrid Laminates. Journal of Reinforced Plastics and Composites. 29(22), 3392-3400.
14. Akman, M.Ö., Oztoprak, B.G., Kutluk, T., 2020. Comparison of Novel Surface Treatments of Al 2024 Alloy for al/cfrp Adhesive Bonded Joints, International Journal of Adhesion and Adhesives, 103, 102721.

15.Logesh, K., Hariharasakthisudhan, P., Rajan, B.S., Moshi, A.A.M., Khalkar, V., 2020. Effect of Multi-walled Carbon Nano-tube on Mechanical Behavior of Glass Laminate Aluminum Reinforced Epoxy Composites. Polymer Composites. 1-12.

16.Zhang, X., Hu, Y., Li, H., Tian, J., Fu, X., Xu, Y., Lu, Y., Chen, Y., Qin, L., Tao, J. 2018. Effect of Multi-walled Carbon Nanotubes Addition on the Interfacial Property of Titanium-based Fiber Metal Laminates. Polym. Compos., 39: E1159E1168.

17. ASTM D 5868-01. 2001. Standard Test Method for Lap Shear Adhesion for Fiber Reinforced Plastic (FRP) Bonding, Annual Book of ASTM Standards.

18. Caiwang, T., Jianhui, S., Baohua, Z., Xiaoting, L., Laijun, W., Bo, C., Xiaoguo, S., Jicai, F., 2020. Effect of Scanning Speed on Laser Joining of Carbon Fiber Reinforced PEEK to Titanium Alloy, Optics \& Laser Technology, 129, 1-10.

19. Boztepe, M.B., Bayramoglu, M., Uzay, C., Geren, N., 2017. Investigation of the Adhesion Bonding Capability Between Different Metals and FRP Composite Layers. Istanbul International Conference on Progres in Applied Science, ICPAS 2017, 1-6.

20. Nassier, A., Nassir, R.S., Birch, W.J., Cantwell, D., Rico Sierra, S.P., Edwardson, G., Dearden, Z.W. Guan., 2020. Experimental and numerical characterization of titanium-based fibre metal laminates, Composite Structures, 245. 